\title{
Scientific community through grid-group analysis
}

\author{
Andrea Cerroni, Zenia Simonella
}

\begin{abstract}
Grid-group map was introduced by Mary Douglas as a tool of anthropological analysis. Several studies have been applying this approach to study social phenomena, but very few concerning the scientific community. The paper aims to bridge the current gap, building sociological ideal-types in the scientific community based on grid-group analysis. Firstly we illustrate the main features of Douglas' grid-group analysis, until the latest studies developed in social sciences. Then, we apply Douglas' approach to a sample of scientists, reporting scholars' stances in the grid-group plane. Finally we suggest a new elaboration of grid-group analysis and some ideas for further research.
\end{abstract}

Key words: grid-group, Mary Douglas, scientific community, sociology of science, symbolic violence, ideal-types 


\section{Introduction}

In a context of scientific controversies and consensus formation, it is worth mapping how different actors adopt different stances ${ }^{1}$ inside the scientific arena. Mapping these stances is relevant to the comprehension of what kind of science (epistemological vision, scientific style, research topic, practices etc.) is adopted by scientists differently positioned on the basis of their scientific life experiences. The grid-group approach (Douglas, 1970, 1973, 1978, 1982) appears as an important analytical tool to better understand such experiences lived by scientists and to build a typology. According to us, such experiences give ground to specific stances and can be classified in Douglas' map, i.e. in terms of rules (grid) and boundaries (group), perceived as opportunities or constraints by scientists.

Many authors have already been using grid-group analysis to study social and political phenomena, in particular the relationship between individuals, nature and risk perception (e.g. Douglas and Wildavsky, 1982).

However, just few studies have been conducted in the sociology of science by historians (e.g. Oldroyd, 1986; Rudwick, 1982) and post-Mertonian sociologists (e.g. Bloor, 1978; Bloor and Bloor, 1982). Our work wants to develop this approach, suggesting a new way to interpret Douglas' schema.

The present paper is organized as follows. Firstly, we consider grid-group analysis as elaborated by Mary Douglas and later applied by others, with a focus on the sociology of science. After describing the methodology, we expose our empirical findings and propose a theoretical integration of Douglas' mapping introducing in each quadrant dominant and subdominant polarities, in connection with a different amount of symbolic violence, along Bourdieu (1994, 1998). Therefore, we present a new elaboration of grid-group analysis and some suggestions for further research, along the new idea that Douglas' quadrants could be looked as a dynamic sequence, capturing some career transitions of scientists during their life.

\section{Grid-group analysis: who I am? How do I have to behave?}

\subsection{Typifying by means of grid-group analysis}

In grid-group map two main dimensions of sociality creates the four Douglas' types. The first one refers to the set of rules to which individuals are subject during their lives (grid); the second one refers to the incorporation of an individual into a bounded group (group). As Mamadouh (1999) points out, idealtypical social positions are constructed to account for cultural diversity in the most parsimonious way as possible, based on these two dimensions.

Before illustrating our research, we have one caveat to make clear: it is not a case of forcing real scientists into theoretically established categories. Following 
Weber (1904/1905), we identify just ideal-types, i.e. heuristic categories useful to assist the researcher, being plausible as reference for the subject studied, but not representing an individual in the real life, nor a statistical average. So, stances can be ascribed to different ideal-types, whether coming from different scientists ${ }^{2}$ or not.

\subsection{Grid-group analysis: Douglas’ cultural types}

Douglas' theory was firstly proposed in Natural Symbols $(1970,1973)$ and Cultural Bias (1978) ${ }^{3}$. Then, it was developed in Sociology of Perception (1982) and Culture and Risk (1982) with Wildavsky; and in the latest publications (e.g. Douglas 2003, 2007) she made some corrections and refinements.

The origins of Douglas' theory were rooted in Durkheim (1912), with regards to the relationship between classification and social experience. Since her Natural Symbols (1970), Douglas was extremely interested in classification, which is at the basis of grid-group theory (Douglas, 2007):

"Classification, like symbolizing, is the creation of culture, or equally one could say that culture is the creation of classifying process. Therefore, the next task head was to attempt a typology of cultures based on a people's need for classification. It would have to emphasize the division of labour and the organization of work. With this object I produce a crude typology intended to account for the distribution of values within a population. The account would show the connection between kinds of social organization and the values that uphold them".

Another reference for her study is Max Weber (1922), especially while she is defining some grid-group type (Douglas, 2007), as it is the case of the charismatic.

What is grid-group analysis and what are its main features? It is a method to identify social pressures on the individual and impressing them in a map.

Grid and group are two social dimensions - group commitment and grid control and their intersection generates four extreme visions of social life (Douglas, 1982). Group (i.e. social incorporation) represents the incorporation of the individual in a group with well-defined boundaries, between those who are within the group (insiders) and those who are outside the group (outsiders). The group dimension is high when the distinction between in and out is high, so that the individual is integrated and protected by the group. Grid (i.e. individuation, insulation) represents the level of prescription interiorized by the individual, the social constraints felt by him/her, while interacting with others. It is high when the individual feels to be as an 'island' under the pressure of a sovereign power.

Quadrant I - Ascribed Hierarchy ${ }^{4}$ (high grid and high group) represents a 
situation in which rationality dominates, or at least this is what is felt by individuals: all roles and tasks are assigned, the division of labour is clearly defined and "everyone remains at one's post". Control, symmetry and recognitions for loyalty dominate this quadrant, as a great love for order in space, in time and among individuals (Douglas, 2003).

Quadrant II - Factionalism (low grid, high group) represents a community of dissidents, having a high level of barriers that separate the inside from the outside. In this social environment, individuals reject hierarchies, formalities and inequalities within the group, and refuses authority and rules. The individual may come to immolate him/herself to the group values.

Quadrant III - Individualism (low grid and low group) is characterized by weak regulation: the individual feels a low level of prescription and low integration within a group, so s/he feels to be a free agent, without any social constraints. In this quadrant, what is at stake is always seen as negotiable: competition for personal advantages is the rule here dominating, while individuals make experience of loneliness and anxiety for reaching excellent performance. However, the possibility of negotiation creates the conditions for mobility and acquisition of prestige and recognition (Douglas, 1982).

Quadrant IV - Atomized Subordination (high grid and low group) is characterized by a low level of incorporation of the individual within a group, but at the same time, the individual experiences a high level of prescriptions and perceives a significant amount of social constraints, relegating him/her into a marginal position. In such a position, the individual performs assigned tasks, being subject to the orders of a superior authority, feeling not to be protected by the group. The feeling of an overwhelming fate is the main characteristic of this quadrant (Table 1).

So, the key concepts associated to every quadrant are, respectively, existing order, fight for justice, personal freedom and anonymous power. According to Douglas (1982), the four quadrants recruit their members on the basis of their way of life, and of their way of thought, too.

It should be noted that grid-group analysis has been criticized about the number of social variables considered (Oldroyd, 1986). Douglas argued that having just the two dimensions would simplify the study of cultures reducing variation to just four different cultural types (Douglas, 1982), in a highly parsimonious model. ${ }^{5,6}$

Grid-group analysis has been developed in the subsequent academic literature, especially in the study of the relationship among individuals, nature and risk perception (Douglas 1985, 1986, 1992; Douglas, Wildavsky 1982; Wildavsky, Dake, 1990; Milton, 1996; Thompson et al., 1990; Thompson et al., 1988; Tansey, O’Riordan, 1999). Douglas's theory has been extensively applied also to political science (Mars, 1982; Davy, 1997) and social sciences. As Mamadouh (1999) 
points out one of the major developments of this theory has been the elaboration of survey tools and questionnaires to study cultural types (e.g. Dake, 1990, 1992; Grendstad, 1990, 1995; Grendstad, Selle, 1999). Recently, it has been applied to study the organizational culture in firms (e.g. Caulkins, 2008; Evans, 2008; Mars, 2008) and risk perceptions and environmental issues, as highlighted by Caulkins (2009). It has also been used to compare different cultures, in terms of beliefs and values (Chai et al., 2009), to study tourism and migration (Duval, 2006), and, more recently, to explain the global economic crisis (Hindmoor, 2010). Douglas' theory has therefore seen many applications in different domains, but we count only a limited number of papers that use grid-group analysis to study the scientific community.

\subsection{Grid-group analysis and the sociology of science}

In his historical reconstruction of sociology of science, Steven Shapin (1982) identified only four papers in which grid-group analysis has been applied. Such papers were looking for a method to study the relationship between scientific thought and social context (Caneva, 1981; Pickstone, 1981; Bloor and Bloor, 1982; Rudwick, 1982). Indeed, this issue was the starting point of Mertonian sociology of science and one of the most difficult tasks for historians of science (Rudwick, 1982). Whilst Pickstone (1981) reserved a short footnote at the end of his paper about Douglas' theory, Bloor (1978), Caneva (1981), Rudwick (1982) and Bloor and Bloor (1982) applied it more extensively. Caneva (1981) rejects the possibility of causally explaining the relationship between social experience and cosmology through grid-group analysis. He rather prefers to view social and scientific reality as both the cause and the effect of human behaviour (Caneva, 1981).

Bloor's historical work (1978) is one of the most prominent on the subject, putting together Lakatos' Proofs and Refutations (1976) and Mary Douglas' Natural Symbols (1973) in order to study the relationship between social pressures and mathematical knowledge. More specifically, the author analyses three types of universities in 19th-century Germany and discovers correspondences between institutional forms and cultural values of these universities. The style in which a famous mathematical anomaly was approached depended upon where the Mathematics departments were positioned within the grid/group typology (Douglas, 2007). Starting from Bloor's work (1978), Rudwick's study uses gridgroup analysis, reconstructing four cognitive styles in geology - abstract, concrete, agnostic, binary - that correspond to the four types of Mary Douglas' map.

Lastly, Bloor and Bloor (1982) empirically verify the relationship between social 
experience and cosmology, starting from interviews and questionnaires to scientists. Although the study was not originally designed to verify such a general hypothesis, the authors directly plotted the interviewed natural scientists on a map and attempted to predict the cosmological vision that shapes the scientists' research activity. This is an important experiment to test grid group analysis on the scientific community, but it seems to be the last one using such theory in the sociology of science. Actually, we don't count any fresh study in which gridgroup analysis is applied to the scientific community. This paper has the aim to fill the gap, developing this research approach in sociology of science.

\section{Methodology}

In the wake of Bloor and Bloor's study, the present article aims to test grid-group analysis, by plotting the interviewees' stances on Douglas' map. In this way we see the scientific experience in terms of rules followed and boundaries perceived by scientists, considering their different stances to point out epistemological visions, scientific approaches and practices.

Aiming to this research object, we analyse forty, semi-structured, in-depth interviews ${ }^{7}$ to women scientists, within a much larger research project on the issue of gender and science. Until now the project counts interviews only to women; indeed it will continue to compare the - potentially different - representations, attitudes and behaviours of women and men inside the scientific community analysing the gender differences in future research.

The questions posed to the interviewees concern: (a) career development, starting from their choice of degree course, up to the present moment; (b) scientific life, including daily life, and (c) general aspects of science, such as their standpoint on objectivity and neutrality, scientific values and issues related to the scientific profession.

To select the scientists to be interviewed we use a purposive sampling strategy with a maximum variation on the dimensions of our interest (Patton, 1990). The scientists were selected starting from the academic staff list published in universities' website, so as to fairly populate academic positions (Table 2), age ranges (Table 3), scientific fields (Table 4$)^{8}$ and geographical locations.

In fact, all our scientists work in the major Italian universities and public institutions, placed in the North, Central and South of Italy (Milan, Turin, Trieste, Rome, Parma, Venice, Naples, Reggio C., Lecce).

To use grid-group analysis for our purpose, we carried out the following method. First of all, we have been looking through all the interviews, extracting statements (quotations) concerning both the grid and group dimensions.

On the basis of these statements, we created a short list of cues specifying the grid 
and group dimensions in further details (Table 5). This method allowed us to structure and to contextualize the grid and group dimensions in the scientific community and to start placing the different scientists' stances in the map. We then interpreted the extracted statements as scientific stances in the position taking of scientists within the field, plotting them in the grid-group map (Figure 1) ${ }^{9}$. Sometimes, quotations may appear doubtful when they are taken apart from the context: but all uncertainties vanish when considering the interview in their whole context. Indeed, typification is the result of the in-depth analysis of words, argumentations, voice pitch, hesitations, exclamations and the general discourse of the scientist interviewed.

Concerning the group dimension, both collective identity and bonds between the individual and the group are relevant. When the group dimension is high, as we saw, the subject perceives himself/herself to be integrated and protected by the group (a discipline, specialty, team group, institution, etc.). Then s/he feels as obligatory to manifest one's loyalty and to clearly establish the boundaries between insiders and outsiders.

Concerning the grid dimension, all aspects linked to social constraints are relevant, both the technical and the moral norms are perceived as compulsory in the scientific community (e.g. Merton, 1973; Mitroff, 1974). When the grid dimension is low, individual contribution is emphasized: meanings and positions are negotiable and the scientist doesn't feel that his/her own originality and creativity are limited. Therefore, achievements are explained in terms of acquisition rather than ascription.

At the beginning of our research, we have tentatively attributed a prevalent type to an interview (every interview was associated to one of Douglas' types). Then, we assigned a cultural type to each statement of each interview, in order to avoid the risk of reducing a real individual to just one ideal-type. Our assumption is that, although it is often possible to identify a prevalent type behind each scientist, it is nevertheless true that scientists may adopt different stances both during their life on the same matter and at the same time on different matters. This assumption allows us to avoiding a static and deterministic interpretation of grid-group theory ${ }^{10}$.

\section{Applying grid-group analysis to a scientific community}

In our interviews, it was possible to identify different scientific stances taken by individuals, on the basis of their social experience (grid-group dimensions). Following Bourdieu (2001), the scientific community can be regarded as a kind of social field in which a disciplinary and biographical habitus ${ }^{11}$ pushes individuals to adopt different stances. Indeed, in the scientific field, individual can be thought 
as the product of a process in the social environment whereby s/he can change both the way of thinking and also his/her position within the field, according to his/her habitus.

In this analysis, we strive to highlight the stances that are typical of each quadrant. It is irrelevant that the declarations are genuine and fit actual behaviour: the important aspect is to identify socio-cognitive references of our women scientists. We now illustrate each quadrant, as defined by the labels of Douglas.

\section{Quadrant I - Ascribed Hierarchy}

In the high grid/high group quadrant we place statements that highlight the commitment individuals show to the group; furthermore they show the integration and the identification voiced by the scientists regarding the role and position assigned to them: thus individual action is enormously limited. Moreover, these statements emphasize procedures over results: the group carries out strict control on procedures.

Beginning with the definition of a hypothesis, continuing with the selection of the variables, right up to experiments on human patients, we must be one team. (Biologist_3, a).

Even if we are in our small laboratory, we are a part of a bigger world. I realized this when I first saw my colleagues who sent articles to be published and other scientists reviewed them. They gave me the idea of a community where there is first of all a willingness to deal with other people, but also the importance of control because one doesn't just get up in the morning and sends an article to Nature. This is not possible, research must be conducted using methods, and therefore there is a review by the community (Biologist_3, b).

In this quadrant, we find the acceptance of epistemological and technical norms and affiliation to a group that ensures the observance of the norms expected by the discipline and, more in general, by the scientific community. Some stances reinforce the intellectual division of labour and clearly trace the boundaries of a disciplinary community: scientists hold objectivity as a moral value and the distinction they feel between natural and human sciences depends precisely on the level of objectivity. In particular, the interviewees from natural sciences trace the highest boundaries between natural sciences (in which they feel to be insiders) and social sciences (whose scholars are considered as outsiders), as follows:

Well, there are two fundamental values, one is this concept of objectivity. The 
scientific community has outlined what can be defined objective and what clearly cannot be considered objective (Physicist_3 a)

I'd like to say, that I do not know about research in the humanities, I am often find myself wondering about what kind of work is carried out by my colleagues in humanities, what are the parameters of objectivity, because my feeling is that they are not able to obtain objective results as we are (Biologist_2 b).

Moreover, other stances emphasize teamwork, with well-defined tasks and roles, in which individual advantages are gained within and through the group: so everyone contributes exclusively in the assigned position. Consider the following statement:

I am very happy to have created a research group that has been working together for 30 years and now we're good together, because I have always been thinking - and I have always been talking with my younger colleagues about this - that divisions are a foolish thing. There is a great project in which everyone gets a piece to be pursued and obtain a personal advantage. I only believe in win-win situations (...) If someone tries to cheat others in a systematic way, s/he is excluded, or the group will not hold together (...) Attention must be paid to ensure that the losers or the winners are not always the same individuals (Biologist_4, a).

All in all, in this quadrant, the emphasis is placed on two different social pressures: one coming from the boundaries of the team, i.e. the discipline or the community in which individual perceives to be incorporated; and the other coming from the norms that they feel to be characteristic of scientific work (e.g. the technical norm of objectivity). These stances show an insider/outsider dynamics: boundaries are traced, pushing the individuals to reach objectives and also pulling them to share group values.

We see the presence of a rational, institutionalized order with well-defined roles and tasks: those individuals not occupying the highest ranks have to conform their scientific attitudes to the norms and to interiorize values of such order. Leaders rule over them, becoming the guarantors of the hierarchical establishment.

\section{Quadrant II - Factionalism}

In the low grid-high group quadrant, statements show strong commitment to the group, similarly to the previous quadrant, but a clear division of labour among members is not acknowledged. Rules and hierarchy are repudiated, so individuals feel to be part of a community of peers (e.g. in a team, a disciplinary field, the 
society as a whole). We report some examples:

I work in a tiny group, there are four of us and I've been working with a colleague for 16 years, we do not have a leader in our group, you may say $<<$ you're just a small group, you do not need a leader $>>$, actually, that's not true... this form of organization, I call it shared leadership, shared, because in fact ... we have always made joint decisions, there has never been a leader ... it happened spontaneously, it just happened ... (Biologist_8, a).

Now I'm interested in participative research, i.e. the awareness of a situated knowledge, which can be found in citizens, environmental associations, and various actors... (Physicist_4, a).

These individuals reject inequalities; as a consequence, as it is argued by Douglas (2007), their group would be handicapped by quarrels on leadership, authority and decision-making. Nevertheless, in this quadrant, it is possible to recognize some charismatic individual with a sectarian ideological vision: $\mathrm{s} / \mathrm{he}$ is bound to the sect values, but s/he also goes outside to find consensus and disciples. The ideal-type to which these stances belong has charisma (Weber, 1922) and symbolic capital (Bourdieu, 1986, 1994), been identifiable with the scientific values and norms themselves.

We need someone to do this, to take the leadership role, however not an authoritarian role, it is important convincing people that it is better for all to do so (Biologist_4, b).

When I proposed myself in substitution of my professor because I began to manage the laboratory, I encountered strong resistances. So I decided to rely on my own reasons ... I decided to follow a management course in order to reinforce my new role as leader (Biologist_2, c).

Especially in-post-academic science, where there are no guarantees of entering the academic world ... we must seek funding, we have to deal with industrial research, using the same methods, the same language, we often have to deal with people who do research in the industry.... This is infrequent in Italy ... but not absent... in this case those who do research are also those who seek funding, who convince people that her/his research is the best one, halfway between propaganda and research and it is not easy to keep an ethical approach (Physicist_6, a). 
The neutrality of science is an invention for defending the status quo, which is ipso facto defined neutral, so that it is unchallengeable. I take it as a corporate institution. It's a little bit like the law. Is the law natural? And what about the rights? According to a radical interpretation, the rights aren't natural! Rights are defined in such a way that they defend the status quo and make it sustainable for a certain power relationship. [...] I have a similar view about neutrality. It is a double-edged thing, it is something with which I have an ambiguous relationship, because I realize that the day you say: "look, science is not neutral, it is full of ideology" the risk is that you drift, we risk to destroy all the good science that has been done till now. I know it is a defence, but I need it. The neutrality of science gives me another stable standpoint for an exchange. If I know that in sayng something you just reflect your prejudices and if you know that it's the same for me, how is dialogue possible? (Economist_2, a).

The charismatic individual in this quadrant looks for proselytes who will give him/her their credit and recognition in order to make changes in the name of the group. Such individual manifests a black-or-white vision, criticises the institutionalized order, either to acquire personal prestige in the field as it is (perpetuating the status quo) or to foreshadow a true new order. In other words, such stances belong to a potential leader looking for disciples, in order to criticize the present mainstream and potentially institutionalize a new school of thought. It is important to stress that, unlike the previous high grid-high group quadrant, actually this quadrant lacks in institutionalization and organization: authority is unprotected, leadership is always challenged and decisions have no coherent institutional framework (Douglas, 2007). The complete and defined formation of a new order only belongs to the Ascribed Hierarchy quadrant.

\section{Quadrant III - Individualism}

The low grid-low group quadrant collects all the individual stances of a free agent, an individual feeling to be free from structural constraints and rules limiting his/her contribution. Consider as examples the following statements:

Behind a great scientific event that has happened over a decade, so many people have possibly contributed to this new idea, using their imagination and creativity (Physicist_2, b).

In society we are present, we not only have the right to speak but to speak with force (Biologist_4, d). 
I chose a path that will not lead me to a high-ranking career, but, let's say, it is the best for me, coherently to my way of understanding life (Physicist_4, b).

I've never been a slave of trends, I have pursued my interests and this is also the reason why I was very distracted, I was interested in all areas, I was not determined enough to concentrate on a single topic, to become the maximum expert for of that subject (Economist_4, a).

Well, the first values are fun and creativity. And then the fact that you are not at the mercy, at least for me, of dogmas, fascinating ideas, but there is an empirical basis in science (Biologist_7, a).

If you do not give scientists the opportunity to waste time with a problem with no immediate application, innovation quickly grinds to a halt. Today, people who work in science are closely linked to the applicability of what they do and this limits our freedom. Let me conclude by saying that the exercise of scientific reasoning is an area of a great freedom of mind, and then scientific thought, which means dealing with a problem, trying to solve it, is an exercise that should be disseminated among young people because it is the exercise of critical thought that is the basis of a democratic citizenship (Biologist_8, b).

I am not a member of IAFEE $^{12}$, although I consider myself a feminist economist, because I don't like this form of ghetto. I will go to the next conference to present a paper, I dialogue with the so-called feminist economists daily, but I feel alienated, for the simple reason that I don't subscribe to that totalitarian choice, because they are people who have been working together for many years, they are a network, but close enough! (Economist_3, a).

I don't cooperate with the same people anymore; at university a researcher has this freedom. It is clear that you pay for this freedom...I'm relatively young as a scientist, I work with young people, so now I don't have a professor as a point of reference, because I ended this relationship with my group of strings physics. Now I still have a good relationship, but I don't collaborate with them... of course I have contacts, but now I'm working with another group...young people ... now I'm slightly like a maverick (...) I would rather do these things and have fun, than be in a group, take a path that interests me less than this freedom (Physicist_5, a).

I have been very flexible during my life. For some reasons aspects I conformed to the male model because I thought it was more adapt, it seemed to be the most 
successful, but in many ways I conformed to the female model, that I mentioned earlier, the ability to put different things together, not to excel in a group, just to promote and favour group work (Biologist_6, a).

Male power is to say that there are rules for everyone else! And you have the power because you break the rules! At university there are those who teach, but your career progresses more if you mess around with it a bit, if you do research, go abroad and publish (Economist_2, b).

Now it may be different for theoretical physicists or very small research groups, but when you do these huge collaborations, it takes determination to pursue their ideas in competition with others. It takes some determination and a certain elbowing capacity when you need it, that is when you have to defend yourself, but it is not always defensive (laughs) (Physicist_2, c).

These stances make frequent use of terms such as freedom, critique, amusement, creativity, curiosity, and individual contribution: all of them show centrality of individual choice, possibility of intellectual mobility and detachment from the group. They also represent the ideal position of an intellectual who feels to be free from any kind of social pressure and who shows curiosity in his/her scientific work, and individualism as well or even an opportunistic behaviour: everything is negotiable. As a result of the absence of both commitment to a group and constraints by a structure, the individual can assess the situation from time to time, looking for personal advantages.

\section{Quadrant IV - Atomized Subordination}

Lastly, in the high grid/low group quadrant, we place stances manifesting resigned acceptance of the status quo and insulation and marginality from the group. These stances do not show a free individual; on the contrary, s/he is subjected to events and with no possibility of negotiation. In our opinion, the following statements express stances that can be interpreted as Atomized Subordination.

The method prevails on the objective (...) the source of authority of our directives lies in the solidity of the method! (...) Leaving aside the solipsist doubt that there is a reality beyond the perception that I have, that's it, everything is method, it's all technique! (Economist_1, a).

We hope in heaven to be judged on the basis of our merit! (Economist_1, b). 
That's ... yeah ... this was a choice I had to make... So I'm not ... uh ... I'm a mainstream economist... my problem is that the mainstream does not know it (Economist_1, c).

Even if the objectives often appear to be neutral, this is not the case of the organization, which is often highly hierarchical. Specifically, it is so closely tied to the achievement of goals that the creativity and curiosity of scientists just isn't allowed (Physicist_2 a).

It is not easy to put forward a different interpretation of the data we collect, because there is very little leeway regarding personal contributions>> (Physicist_2, a).

Such stances belong to women economists, physicists and biologists being deeply involved in their field of studies and perceiving a vision of the scientific method thought as obligatory and ineluctable. In spite of the diversity of epistemic cultures, these scientists indicate the same social experiences in the scientific environment: they perceive themselves to be part of a whole system that limits their individual contribution. After all, they show acknowledgement of social constraints, having de facto internalized norms and values of the scientific community as principles in their decision-making. In these excerpts, the main concerns are about the data, the method, the nature: so, the emphasis falls on the procedures, rather than on the results, that remain unquestioned precisely as the principles. We don't find neither free curiosity nor free creativity; but we find different forms of marginality from the mainstream (Table 6).

Lastly, we remark that in our study we didn't report any relevant statement of sociologists about their scientific experience. We suppose this is due to the reflexive practice (Bourdieu, 2001) peculiar to sociologist's profession and to the fact that our women sociologists were chosen among gender scholars: interviewing them on gender matters, the scientific elaboration of their own social experience should make the grid-group analysis less interesting (or at least more difficult to be applied) then in the other cases. So, according to us, sociology should deserve a consideration apart in future research.

\section{Conclusions}

This analysis shows that scientists' social experience in the scientific field is in correspondence to a specific perspective or point of view on science and scientific community. In our opinion, the idea of this correspondence seems to be contiguous to Pierre Bourdieu's field theory, in which he argues the dynamic (not 
causal) relationship between position, disposition (habitus) and stance (e.g. Bourdieu, 2001; see also Albert, Kleinman, 2011). Putting together Douglas' and Bourdieu's analyses is a promising theoretical perspective.

We found four scientific visions in the grid-group map, in analogy with the cosmological vision of Schwarz and Thompson (1990). However, based on our results, we suggest that the four Douglas types can be further refined: according to us, two polarities can be identified ${ }^{13}$, corresponding to a different amount of suffered symbolic violence. In particular, for every quadrant, we find one type that exercises a symbolic power and another type that is victim of a symbolic violence. The concept of symbolic violence was theorized by Bourdieu (1998) to explain the relationship between the dominator and the dominated, by means of a form of violence that he defined as sweet and invisible. At the base of the concept of symbolic violence, we find the idea of dominance without discipline: where those being dominated have internalized and inscribed in their body the disposition to submission to a social order, that render it at the same time spontaneous and extorted (Bourdieu 1998: 38). The main characteristic of symbolic violence is the adherence by the dominated to thought patterns, that are the product of the embodiment of power relations (Bourdieu, 1998:34), generating the symbolic violence that the dominated undergo: in fact, the dominated apply categories constructed from the point of view of the dominant to the relations of domination, thus making them appear as natural (Bourdieu, 1998: 35). It is for this reason that the dominated is an accomplice of the dominator.

We propose eight new labels that represent vivid and well-defined figures that can make tangible the ideal-types, in four couples, one for each quadrant, respectively: Ruler and Bishop, Organizer and Vanguard, Free Spirit and Free Rider, Relegated and Operative.

Quadrant I - In the high grid-high group quadrant, the Ruler is the leader of an institutionalized social order, whose public recognition once gave origin to the mainstream. Detachment (à la Norbert Elias) is necessary in order to lead institutionalization and to become the guardian of a sacred order. The Bishop, on the contrary, is committed to the group and accepts the assigned role. As a bureaucrat of the scientific community, s/he is embedded in the establishment, collocated in a recognized role. So, the Bishop is not the one who writes the rules, but $\mathrm{s} /$ he is the messenger who respects them and allows them to be respected, being therefore subjected to a high symbolic violence.

Quadrant II - In the low grid-high group quadrant, we identify two different types both seeking proselytes to create a peer group, in complete adherence to the same ideal and end. However, whilst the Vanguard is looking for disciples aiming at a consensus and consolidated leadership, the Organizer uses his/her charisma to adumbrate a new institutionalization (e.g. a new school of thought). It is necessary 
that s/he has charisma and high rational detachment, in order to convey roles and rules to build a true new order, which receives wide consensus and is destined to survive.

Quadrant III - The low grid-low group quadrant splits into two types of individualism. The first type is Free Spirit characterized by stances distant from group commitments, free from patent structural constraints, expressing an autonomous and possibly critical position concerning the existing order. The second type - Free Rider - is an opportunistic individual who manipulates the rules of the game to his own advantage. Apparently free, s/he however has to be both careful in publicly expressing his/her own opinions and timely when seizing the opportunities generated by those ruling the field. In this quadrant, in one subtype or in the other, we should place many stances of the typical free intellectual.

Quadrant IV - In the high grid-low group quadrant, Douglas' Atomized Subordination splits into two distinguishable sub-types, both perceiving the weight of the structure without commitment to the group: whilst the Relegated is on the margins of the scientific community, living with (partial) detachment and without worrying about this state, the Operative feels to be constrained in a marginal role, functional to an (anonymous) mechanism. While the first one is out of the game, the last one gives a (not creative) contribution to it, as a part of the mechanism. S/he is therefore more subjected to the symbolic violence than the first type is.

Although the dominant types - Ruler, Organizer, Free Spirit and Relegated belong to different quadrants, they share common features: they are rather dominant in their quadrant and manifest different forms of detachment. They are not mere performers, but individuals with a symbolic power enabling them to rule or refuse, criticize or subvert the mainstream.

Their counter-types - Bishop, Vanguard, Free Rider and Operative - are subdominant in matter of symbolic power within the scientific community. They are simply performers, being victims of symbolic violence, although in quite different ways (Figure 2).

Lastly, we remark that our study shows that Douglas' model is not necessarily a static and deterministic one; quite to the contrary, it classifies individual stances on the basis of what is actually at stake, without crystallizing an individual, reducing him/her to an abstract type. Through the lenses of the model, we can look at the intellectual life-cycle of a scientist ${ }^{14}$.

As an example, we can easily portray a successful scientist moving across the quadrants, starting from the low grid-low group one (Individualism). ${ }^{15}$ In this quadrant the individual is a free agent, expressing creativity, generating knowledge in an essential tension between tradition and innovation (Kuhn, 1977). Then, the scientist, after developing a systematic thought, would seek disciples 
with the aim to build an institutionalized school of thought (Factionalism). S/he would establish and consolidate a hierarchical order over time (Ascribed Hierarchy). And finally, the life cycle should come to a close, when the school of thought is a part of the scientific memory (handbooks) after being completely assimilated or forgiven by the taken-for-granted part of the scientific community (Atomized Subordination).

In conclusion, grid-group analysis appears to be an important heuristic model to study the scientific community, because it enables the recognition of scientists' stances that can potentially prejudice or favour both innovation and career in the scientific community.

Furthermore, beyond the specificity of our research design, our typification can be applied to the general scientific community, when dominant and subdominant polarities are included. It is our belief that the polarities are linked to differing degrees of power, especially occurring in the form of symbolic capital (Bourdieu, 1986, 1994) in all three forms of knowledge, acquaintance and acknowledgement, leading individuals to various positions in the field. Testing these hypotheses in a wider sample, also including male-scientists and scientists coming from other disciplines, is a future step of our research, as it is a deeper analysis of symbolic capital as far as scientific community is concerned. 


\section{Endnotes}

1 Here we consider a stance as a disposition, a posture or a standpoint about a specific scientific matter expressed in the discursive position-taking how it is reported in an interview.

2 We are deliberately giving the ideal-types an interpretation that places our reflection beyond the traditional dichotomy between methodological individualism, which is often taken as (a simplistic reduction of) Weber's thought, and methodological holism, which is analogously taken as (a simplistic reduction of) Durkheim's thought. We believe to be following Mary Douglas' methodological direction, as she draws freely from both theoretical tenets.

3 According to Spickard (1989), Douglas moves from a position that says "there is a strong tendency to replicate in symbolic form Social Situations" to another that says "one must look to the cosmology beneath the overt pattern of power which it realizes”. The first position is typical of Natural Symbols (1970) and Cultural Bias (1978), in which social experience and cosmology are isomorphic, that is, every social context develops an "argument" that naturally supports it; whilst the second belongs to Natural Symbols (1973) in which cosmology preserves and guarantees social order: there appears to be a causal relation between social experience and cosmology, that in the 1970 edition and in the 1978 book does not seem to be present.

4 Regarding the survey conducted by Braman and Kahan (2003), on gun-risk perceptions, Douglas argues that it is necessary to eliminate as much as possible the bias in the Ascribed Hierarchy's quadrant, that is often linked to the connotation that the word hierarchical can take on within a national culture.

5 Through this simplified model, argues Mary Douglas, it is possible to carry out an analysis otherwise difficult to conduct. In addition, although it is legitimate to introduce changes, the four identified types are inevitably leading individuals in their quadrant of affiliation.

6 In the studies about risk perception, the four cultural types are very effectively denominated, respectively, 
Hierarchical, Egalitarian, Individualist and Fatalist (Schwartz and Thompson 1990).

7 The interviews were conducted in Italian by the authors. All the statements that were selected for each quadrant were translated in English in order to be considered in this paper.

8 We are well aware that different disciplines mean actually different epistemic cultures (Knorr Cetina, 1999), different opportunities and logics (Bourdieu, 2001) and different science-society relationships. However, while direct confrontations among ideal-types for different disciplines should be deepened, the grid-group typology is intrinsically relational, so it maintains its validity for our aim.

9 The Low-High values were qualitatively attributed to isolate ideal-types according to the aim of Mary Douglas' simplified map. The philosophy of grid-group analysis is to build a typology with few manageable ideal-types, allowing the investigator to easily highlight social regularities.

10 When Oldroyd (1986) applies grid-group analysis to the biographies of Darwin and Linnaeus, the historian tries to position each of them in a cultural map, disregarding the ideal-type methodological characteristics. As to be expected, he has difficulties attributing only one type to each scientist in fleshand-blood, due to complexity and dynamics of social life.

11 According to Bourdieu (2001: 42), there are disciplinary habitus and also some specific habitus linked to biography (social and educational origin, gender, age etc.).

12 IAFE: International Association of Feminist Economists.

13 An outline of this distinction can be found in Douglas (2007) with regards to the fatalist type.

14 In abstract, there are several possibilities for a scientist during her/his life, going from a static positioning in one quadrant to a complete cycle across the diagram. Here we focus on the most general, intuitive and the most useful for our research. We should remind that, precisely because Mary Douglas' types are idealtypes, real individuals can be typified in different ways during their lifetime. Furthermore as we extensively argued, a scientist in the real world can also adopt different stances at the same time on 
different matters. In all these cases, the same individual could be classified time by time in different idealtypes without any contradiction in the typification.

15 In any case, the socialization process in scientific life, begins in the early stages of a career, including rites of passage, norms, and values that characterize the scientific community (Veblen 1899; Bourdieu 1982). 


\section{References}

Albert M, Kleinman D (2011) Bringing Pierre Bourdieu to Science and Technology Studies. Minerva 49 (3): 263-273.

Bloor C, Bloor D (1982) Twenty Industrial Scientists: a preliminary exercise. In: Douglas M (ed.) Essays in the Sociology of Perception. London: Routledge \& Kegan Paul, pp.83102.

Bloor D (1978) Polyhedra and the abominations of Leviticus. British Journal for the History of the Science 11: 245-72.

Bourdieu P (2001) Science of Science and Reflexivity. Cambridge, UK: Polity Press 2004.

Bourdieu P (1998) Masculine Domination. Cambridge, UK: Polity Press, 2001.

Bourdieu P (1994) Raisons Pratiques. Sur la théorie de l'action. Seuil: Paris.

Bourdieu P (1986) The forms of capital. In: Richardson J (ed.) Handbook of Theory and Research for the Sociology of Education. New York, Greenwood, pp.241-258.

Bourdieu P (1982) Leçon sur la leçon. Paris: Editions Le Minuit.

Braman D, Kahan D (2003) More Statistics, Less Persuasion: A Cultural Theory of Gun-Risk Perceptions. Yale law School, Working Paper 5.

Caneva K (1981) What should we do with the monster? Electromagnetics and the psychosociology of knowledge. In: Mendelsohn E, Elkana Y (eds.) Sciences and Cultures: Anthropological and $H^{a}$ Studies of the Sciences. Dortrecht, Holland: Reidel, pp.101-131.

Caulkins D (2008) Re-theorizing Jim Collins's culture of discipline in Good to Great. Innovation: The European Journal of Social Science Research 21(3): 217-232. Special Issue: Cultural Theory and Management.

Caulkins D (2009) Grid-group analysis. In: Svendsen T, Svendsen GLH (eds) Handbook on social capital. Williston, VT: Edward Elgar.

Chai S, Liu M, Kim M S (2009) Cultural Comparisons of Beliefs and Values: Applying the Grid-Group Approach to the World Values Survey. Beliefs and Values 1(2).

Dake K (1992) Myths of nature: cultural and social construction of risk. Journal of Social Issues 48(4): 21-37.

Dake K (1991) Orienting dispositions in the perception of risk: an analysis of contemporary world views and cultural biases. Journal of Cross-Cultural Psychology 22(1): 60-81.

Dake K (1990) Technology on Trial: Orienting Dispositions Toward Environmental and Health Hazards. PhD thesis. Berkeley: University of California.

Dake K, Thompson M (1993) The Meanings of sustainable development: household strategies for managing needs and resources. In: Wright S, Deitz T, Borden R, Young G, Guagnano G (eds) Human Ecology: Crossing Boundaries. Forth Collins, Colorado: The Society for Human Ecology, p.421-436.

Davy B (1997) Essential Injustice, When Legal Institutions Cannot Resolve Environmental and Land Use Disputes. Wien: Springer-Verlag.

Douglas M (2007) A History of Grid and Group Cultural Theory. URL: www.chass.utoronto.ca/epc/srb/cyber/douglas1.pdf.

Douglas M (2003) Being Fair to Hierarchists. University of Pennsylvania Law Review 151(4): 1349-1370.

Douglas M (1999) Four cultures: the evolution of a parsimonious model. GeoJournal 47: 411415.

Douglas M (1992) Risk and Blame: Essays in Cultural Theory. London: Routledge.

Douglas M (1986) How Institutions Think. Syracuse NY: Syracuse University Press.

Douglas M (1985) Risk Acceptability according to the Social Sciences. New York: Russell Sage Foundation.

Douglas M (ed) (1982) Essays in the Sociology of Perception. London: Routledge and Kegan 
Paul.

Douglas M (1978) Cultural Bias. Royal Anthropological Institute Occasional Paper, 35, London: Royal Anthropological Institute.

Douglas M (1973) Natural Symbols, Explorations in Cosmology. First Vintage Books edition, New York: Vintage Books.

Douglas M (1970) Natural Symbols, Explorations in Cosmology. London: Barrie \& Rockliff.

Douglas M, Wildavsky A (1982) Risk and culture: an Essay on the Selection of Technological and Environmental Dangers. Berkley: University of California Press.

Durkheim É (1912) Les formes élémentaires de la vie religieuse. Paris: Alcan.

Duval D T (2006) Grid/Group Theory and its Applicability to Tourism and Migration. Tourism Geographies. An International Journal of Tourism Space, Place and Environment 8(1) : 1-14.

Elias N (1987) Die Gesellschaft der Individuen. Frankfurt: Suhrkamp.

Elias N (1983) Engagement und Distanzierung. Arbeiten zur Wissenssoziologie. Frankfurt: Suhrkamp.

Evans J A (2008) Dealing with dissent: whistleblowing, egalitarianism, and the republic of the firm. Innovation: The European Journal of Social Science Research 21(3): 267-279. Special Issue: Cultural Theory and Management.

Grendstad G (1995) Party followership and leadership in Norway: A Political Culture Approach. Party Politics 1(2): 221-243.

Grendstad G (1990) Europe by Cultures, An Exploration in Grid/Group Analysis. Graduate Thesis. University of Bergen.

Grendstad G, Selle P (1999) The formation and transformation of preferences, cultural theory and postmaterialism compared. In Thompson $\mathrm{M}$, et al. (eds) Cultural Theory as Political Science. London: Routledge, pp.43-58.

Hindmoor A (2010) The Banking Crisis: Grid, Group and the State of the Debate. Australian Journal of Public Administration 69 (4): 442-456.

Knorr-Cetina, K. (1999) Epistemic cultures: how the sciences make knowledge. Cambridge, MA: Harvard University Press.

Kuhn T (1977) The Essential Tension: Selected Studies in Tradition and Change. Chicago: Chicago University Press.

Lakatos I (1976) Proofs and Refutations: The Logic of Mathematical Discovery. Cambridge: Cambridge University Press.

Mamadouh V (1999) Grid-Group Cultural Theory: An introduction. GeoJournal 47: 395-409.

Mars G (1982) Cheats at work, an anthropology of workplace crime. London: George Allen and Unwin.

Mars G (2008) Corporate cultures and the use of space: an approach from Cultural Theory. Innovation: The European Journal of Social Science Research 21(3): 185-204. Special Issue: Cultural Theory and Management.

Merton R K (1973) The Sociology of Science: Theoretical and Empirical Investigations. Chicago: The University of Chicago Press.

Milton K (1996) Environmentalism and Cultural Theory. London: Routledge.

Mitroff I (1974) Norms and counter-norms in a select group of the Apollo moon scientists: case study of the ambivalence of scientists. American Sociological Review 39 (4): 579595.

Oldroyd D (1986) Grid-group Analysis for Historians of Science? History of Science XXIV: 145-171.

Patton M Q (1990) Qualitative evaluation and research methods. Newbury Park, CA: Sage Publications.

Pickstone J (1981) Bureaucracy, Liberalism, and The Body in post-Revolutionary France: Bichat's physiology and the Paris School of Medicine. History of Science XIX: 115- 
142.

Rayner S (1988) The rules that keep us equal. In: Flanagan J, Rayner S (eds) Rules, Decisions and Inequalities in Egalitarian Societies. Avebury: Aldershot, pp.40-42.

Rayner S (1991) A Cultural Perspective on the structure and implementation of global environmental agreements. Eval. Rev. 15: 75-102.

Rudwick M (1982) Cognitive styles in geology. In: Douglas M (ed) Essays in the Sociology of Perception. London: Routledge and Kegan Paul, pp.219-241.

Schwarz M, Thompson M (1990) Divided we stand: Redefining politics, technology, and social choice. Philadelphia: University of Pennsylvania Press.

Shapin S (1982) History of science and its sociological reconstruction. History of science XX: $157-211$.

Spickard J (1989) A Guide to Mary Douglas's Three Versions of Grid/Group Theory. Sociological Analysis 50(2): 151-170.

Tansey J, O’Riordan T (1999) Cultural theory and risk: a review. Health, Risk, Society 1(1): 71-90.

Thompson M, Ellis R, Wildavsky A (1990) Cultural Theory. Boulder, Co: Westview Press.

Thompson M, Rayner S, Ney S (1998) Risk and governance, Part II: Policy in a Complex and Plurally Perceived World. Government and Opposition 33(3): 330-354.

Veblen T (1899) The Theory of Leisure Class. Pennsylvania State University.

Weber M (1904-5) Die protestantische Ethik und der Geist des Kapitalismus. Archiv für Sozialwissenschaft und Sozialpolitik 20-21. Tübingen: Mohr.

Weber M (1922) Wirtschaft und Gesellschaft. Tübingen: Mohr.

Wildavsky A, Dake K (1990) Theories of risk perception: who fears what and why? Daedalus 119: 41-60.

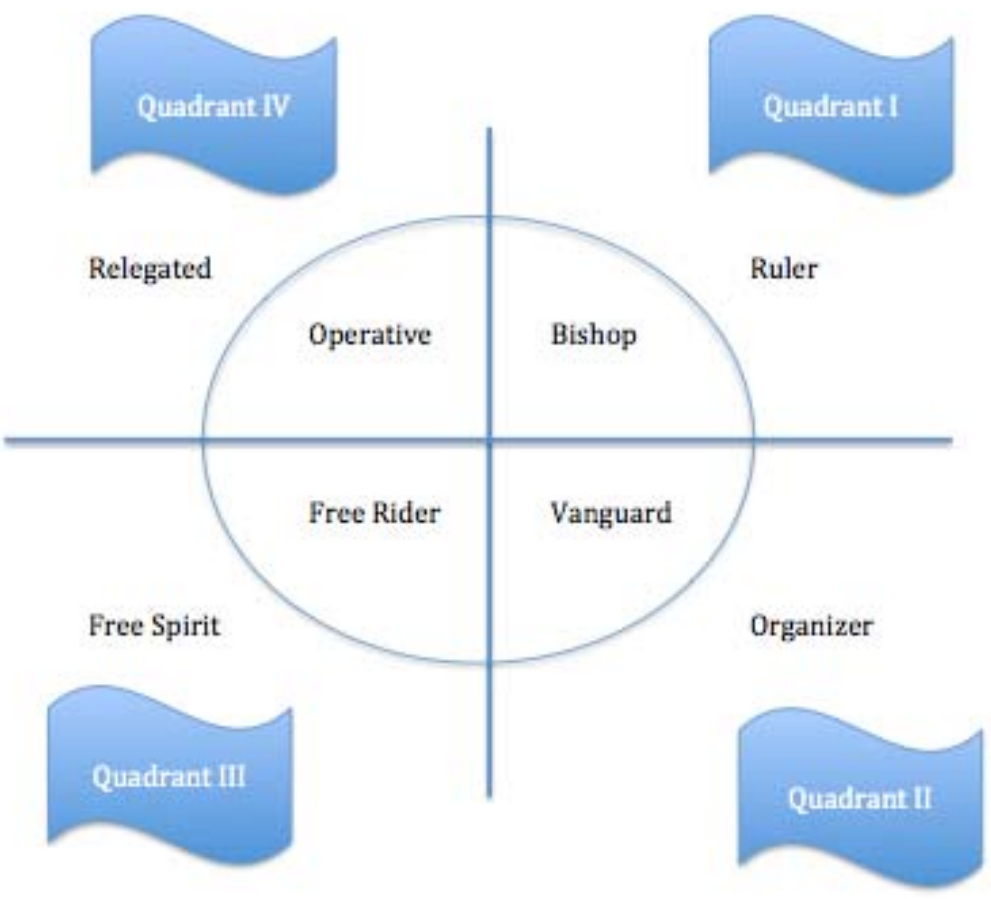


Table 1. The grid-group map (Douglas, 1982)

\begin{tabular}{|c|c|c|}
\hline \multirow{4}{*}{ Grid } & Atomized Subordination (IV) & Ascribed Hierarchy (I) \\
\cline { 2 - 4 } & High Grid/Low Group & High Grid/High Group \\
& Individualism (III) & Factionalism (II) \\
& Low Grid/Low Group & Low Grid/High Group \\
\hline
\end{tabular}


Figure 1. Methodology
A. Reading and Analysis
B. Categorization
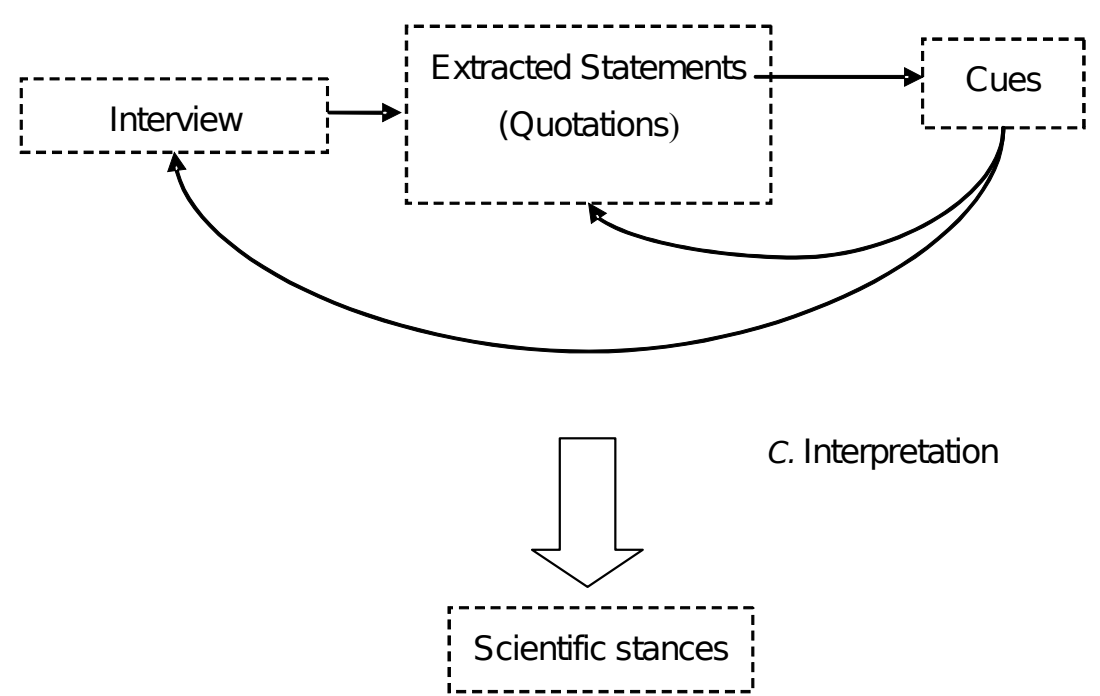
Table 5. Grid-group cues

\section{(High) Group Cues}

Group: the body of commitments to the community and the identification in its values, a community

being a research team, an institution, a disciplinary community

To emphasize the working group, in which all tasks are well defined but strictly

interdependent

To express commitment and loyalty to the group

To emphasize the boundaries between own group and others

To perceive oneself protected by a community with which the individual shares values

(High) Grid Cues

Grid: the roles and the structural constraints on the individual

To emphasize disciplinary boundaries and tradition

To express low margins for bargaining and renegotiation of position

To emphasize division of labour, assignment of tasks and roles within a hierarchical

network that has already been stated and ascribed 
Table 2. Academic Positions

\begin{tabular}{|r|r|}
\hline Academic Positions & N. \\
\hline Post doc & 6 \\
\hline Assistant Professor & 16 \\
\hline Associate Professor & 6 \\
\hline Full Professor & 12 \\
\hline
\end{tabular}


Table 3. Age Ranges

\begin{tabular}{|r|r|}
\hline Age & N. \\
\hline$<35$ & 5 \\
\hline $36-40$ & 13 \\
\hline $46-60$ & 12 \\
\hline$>60$ & 10 \\
\hline
\end{tabular}


Table 4. Scientific Fiels and sub-fields

\begin{tabular}{|r|r|r|r|r|}
\hline Physics & $\mathbf{1 0}$ & & Biosciences & $\mathbf{1 0}$ \\
\hline Foundamental Physics (String and Particle Physics) & 5 & & Neuroscience & 2 \\
\hline Applied Physics (Medical, Atmosphere, Material) & 5 & & Biotechnology & 4 \\
\hline & & & Biology & 4 \\
\hline & & & & \\
\hline Economics & $\mathbf{1 0}$ & & Sodology & $\mathbf{1 0}$ \\
\hline Political Economy & 10 & & General Sociology & 10 \\
\hline
\end{tabular}


Table 6. Stances quadrant by quadrant

\begin{tabular}{|l|l|}
\hline ECO_1 (a) & BIO_2 (b) \\
ECO_1 (b) & BIO_3 (a) \\
ECO_1 (c) & BIO_3 (b) \\
& BIO_4 (a) \\
BIO_2 (a) & \\
PH_2 (a) & PH_3 (a) \\
\hline PH_2 (b) & \\
PH_2 (c) & PH_4 (a) \\
PH_4 (b) & PH_6 (a) \\
PH_5 (a) & BIO_4 (b) \\
BIO_4 (d) & \\
BIO_6 (a) & BIO_2 (c) \\
BIO_7 (a) & BIO_8 (a) \\
BIO_8 (b) & \\
ECO_2 (b) & \\
ECO_3 (a) & \\
ECO_4 (a) & \\
\hline
\end{tabular}

N.B. Dominant $=$ bold; subdominant $=$ italic 
Figure 2. Grid-group slots revised for the scientific community

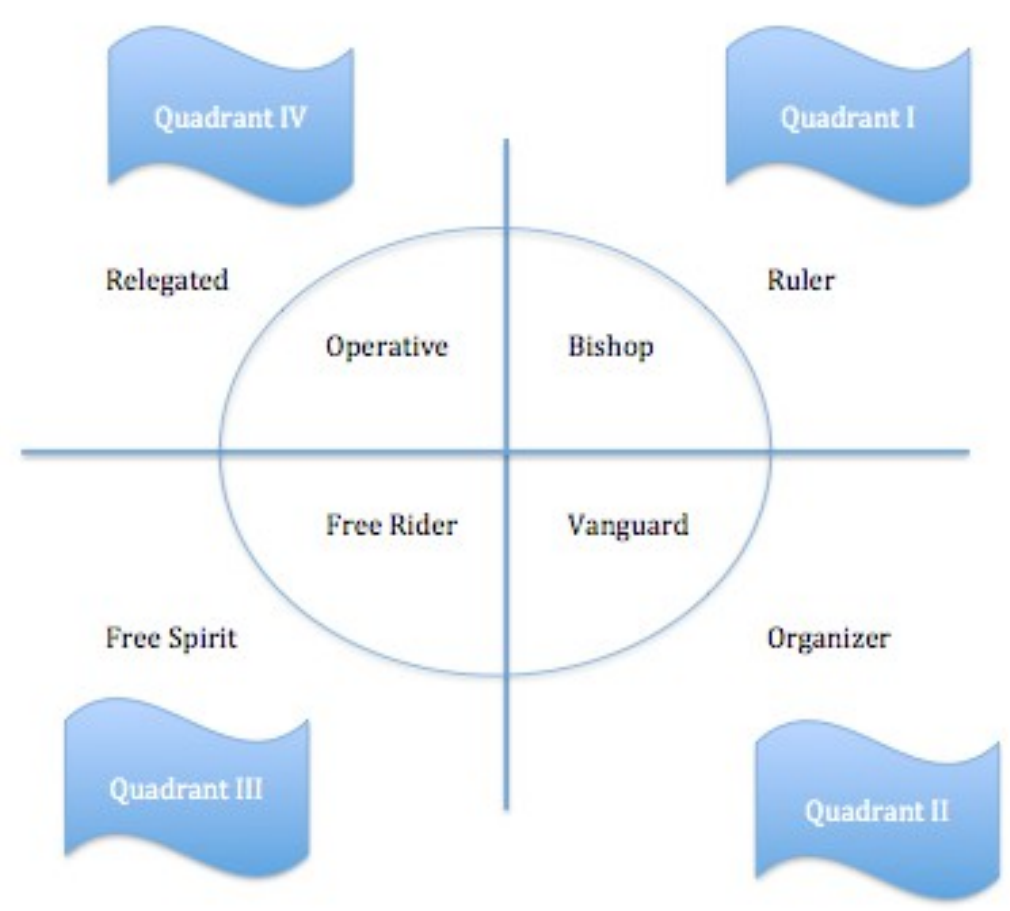

